\title{
RF MEMS SWITCHES WITH METAL ALLOY ELECTRIC CONTACTS
}

\author{
Ronald A. Coutu, Jr." and Paul E. Kladitis \\ Air Force Institute of Technology, AFIT/ENG, Wright Patterson AFB (WPAFB), OH, 45433
}

\author{
LaVern A. Starman \\ Air Force Research Laboratory - Sensors \\ Directorate, Hanscom AFB, MA, 01731
}

\section{ABSTRACT}

This paper is the first to report on the design, fabrication, and testing of radio frequency (RF) microelectromechanical systems (MEMS) contact switches with metal alloy electric contacts. The micro-switches in this study were fabricated with sputtered gold $(\mathrm{Au})$-platinum $(\mathrm{Pt})(\mathrm{Au}-(6 \%) \mathrm{Pt})$ and gold-palladium $(\mathrm{Pd})(\mathrm{Au}-$ (2\%)Pd) alloy contact metals. For comparison, micro-switches with sputtered $\mathrm{Au}$ electric contacts were also fabricated and tested. The micro-switches with alloy electric contacts exhibited contact resistance $\left(R_{c}\right)$ values between 1-2 $\Omega$ and switching lifetimes that were approximately 2-2.7 times greater than micro-switches with sputtered Au electric contacts.

\section{INTRODUCTION}

Reliable micro-switches with $R_{c}<1-2 \Omega$ and capable of switching lifetimes $>10^{8}$ "hot-switched" cycles are needed for future RF applications like space-based and phased array radar. Previous work concentrated on optimizing mechanical designs rather than investigating different electric contact metallurgies [1]. Notable exceptions are Majumder, et al.'s and Duffy, et al.'s utilization of "platinum group" and platinum $(\mathrm{Pt})$ contact metals, respectively $[2,3]$. These metals were chosen over gold for their increased hardness and improved wear characteristics. In order to achieve acceptable contact resistance values, Majumder, et al.'s switches required multiple (i.e. 4 to 8 ), parallel contacts and were packaged in a hermetic environment while Duffy, et al.'s switches required high actuation voltages of $>\sim 80 \mathrm{~V}$. Schimkat studied gold-nickel (Ni) alloy (Au-(5\%)Ni) macro-switch contacts in a low-force test configuration but not actual MEMS switches [4].

In this study, contact resistance and switching lifetime were investigated using MEMS test structures fabricated with sputtered metal contact materials. The alloys and compositions in this study were chosen to avoid two-phase regions, intermetallic compounds, high actuation voltages, and allow for the testing of un-packaged devices. These considerations help ensure that device fabrication is consistent and repeatable. The contributions of this work include: the design and fabrication of cantilever-style, series switches with sputtered $\mathrm{Au}$ and sputtered metal alloy electric contacts, the use of $\mathrm{Au}-(6 \%) \mathrm{Pt}$ and $\mathrm{Au}-(2 \%) \mathrm{Pd}$ alloys, the fabrication of hemispherical-shaped upper contacts using timed reflow, and a comparison of measured pull-in voltage, contact resistance, and switch lifetime test results.

\section{DESIGN AND FABRICATION}

\author{
Robert L. Crane \\ Air Force Research Laboratory - Materials and \\ Manufacturing Directorate, WPAFB, OH, 45433
}

In metal contact micro-switches, initial switch closure is defined by the pull-in voltage. At pull-in, physical contact between the switch's electric contacts is established with minimal contact force. As the actuation voltage is increased, contact force increases resulting in lowered contact resistance [5]. Contact resistance and switch lifetimes were investigated using the cantilever test structures shown in Figures 1 and 2.

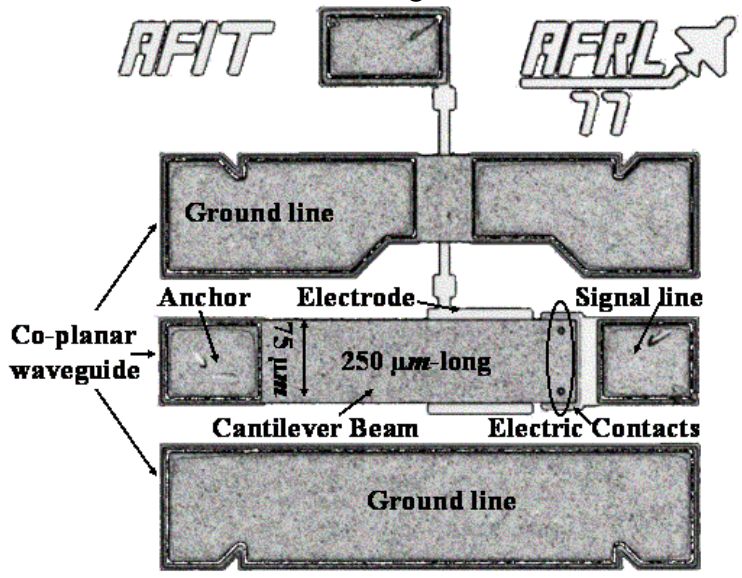

Figure 1. Captured video image of an electrostatically actuated, cantilever-style, RF MEMS switch ( $75 \mu \mathrm{m}$-wide by $250 \mu \mathrm{m}$-long). The electric contacts located at the end of the beam and the actuation electrode's center is located $150 \mu \mathrm{m}$ from the anchor.

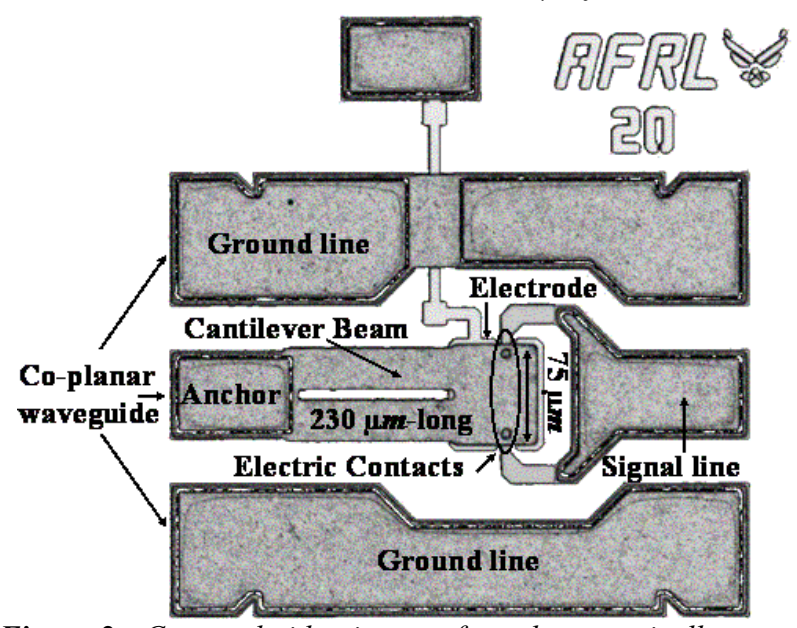

Figure 2. Captured video image of an electrostatically actuated, cantilever-style, RF MEMS switch ( $75 \mu \mathrm{m}$-wide by $230 \mu \mathrm{m}$-long). The electric contacts and actuation electrode co-located near the end of the beam.

\footnotetext{
* Corresponding Author: R. A. Coutu, Jr., AFIT/ENG, 2950 Hobson Way, WPAFB, OH, 45433

Tel: (937) 255-3636 ext 4595, Fax: (937) 656-4055, Email: ronald.coutu@afit.edu or ronald.coutu@wpafb.af.mil
}

The views expressed in this article are those of the authors and do not reflect the official policy or position of the United States Air Force, Department of Defense, or the U.S. Government. 
The effects of changing actuation voltages and applied contact force locations were investigated in this study. In the device shown in Figure 1 the electric contacts are located at the end of the beam while the center of the actuation electrode is located $150 \mu \mathrm{m}$ from the beam's anchor. The force placement in this design allows for mechanical cleaning (i.e. wiping) of the switch's electric contacts with each switch actuation. In addition, this design allows for overdriving the beam to collapse. In the Figure 2 device, the electric contacts and actuation electrode are co-located in the vicinity of the electric contacts (i.e. near the beam's end). This allows for the application of higher actuation voltage and consequently higher contact force without increasing the likelihood of collapsing the beam onto the bottom electrode.

The micro-switches in this study were fabricated as part of a co-planar waveguide (CPW) structure on highly resistive sapphire substrates. Three wafers of devices, each with different contact metals (i.e. sputtered $\mathrm{Au}, \mathrm{Au}-(6 \%) \mathrm{Pt}$, and $\mathrm{Au}-(2 \%) \mathrm{Pd})$, were individually fabricated using the fabrication process illustrated in Figure 3. Refer to Figure 3 for the following discussion.

\section{Evaporated gold bottom metal}

(anchor, electrode, and lower contact)

$$
\text { (a) }
$$

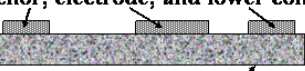

Sapphire Substrate
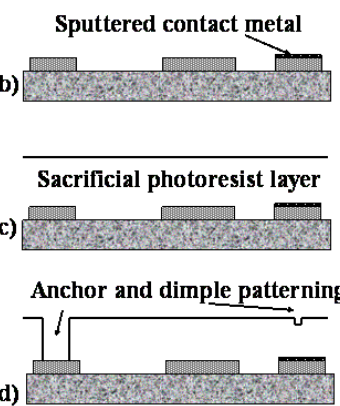
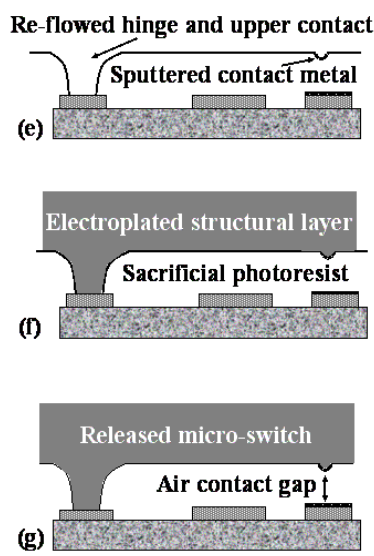

Figure 3. Illustration of the micro-switch fabrication process.

The actuation electrode and lower electric contact layers were approximately $3000 \AA$ of evaporated $\mathrm{Au}$ patterned using a standard metal lift-off technique (a). A thin (200 $\AA$-thick) chromium $(\mathrm{Cr})$ layer was used under the evaporated $\mathrm{Au}$ layer to help the Au remain adhered to the substrate. The lower electric contact metal was sputter deposited (500 §-thick) and patterned using a metal lift-off technique (b). Due to the conformal nature of sputtered materials, "wings" or raised metal "edges" shown in Figure 4, remain after performing sputtered metal lift-off.

The beam's gap or sacrificial layer was approximately $3 \mu \mathrm{m}$ thick and created using MicroChem's polydimethylglutarimide (PMGI) based photoresist (c) [6]. The switch's hinge geometry was defined in the sacrificial photoresist using standard photolithography techniques while the upper contact geometries were defined by a partial expose and develop of the sacrificial photoresist layer (d). A timed re-flow in an oven with flowing nitrogen was used to reform the dimple into a hemisphericalshaped upper contact bump (e).

The upper contact metals were also sputter deposited (500 $\AA$ thick), and patterned into the switch's dimple area using standard photolithography techniques (e). The excess metal (outside of the dimple area), however, was removed using an etch-back technique, instead of lift-off, to avoid damaging the sacrificial photoresist layer. The upper contact material, located only on the hemispherical-shaped upper contact, is highlighted in Figure 4.

After electroplating the cantilever's gold structural layer $(\sim 5$ $\mu m$-thick) (f), the devices were released using a $\mathrm{CO}_{2}$ critical point dryer and tested to ensure proper operation and performance (g).

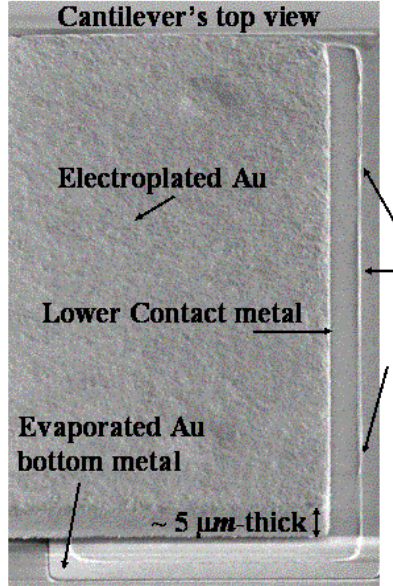

(a)

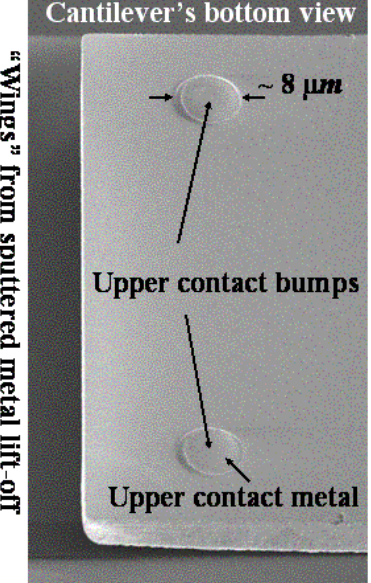

(b)
Figure 4. Scanning electron micrograph (SEM) images of a 75 $\mu \mathrm{m}$-wide by $250 \mu \mathrm{m}$-long beam: (a) top view (b) bottom view.

Single-phase (i.e both elements have the same crystal structure) $\mathrm{Au}-(6 \%) \mathrm{Pt}$ and $\mathrm{Au}-(2 \%) \mathrm{Pd}$ metal alloy compositions were chosen as the electric contact materials to avoid two-phase regions (i.e. mixture of two different phases) and intermetallic compounds (i.e. crystal structure that is different from either element). The Au-Pt and Au-Pd phase diagrams for are provided in Figure 5 [7].

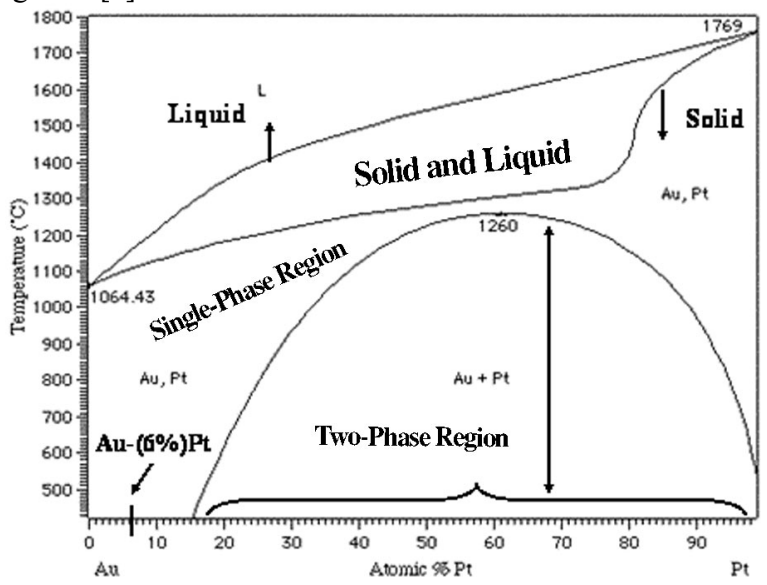

(a)

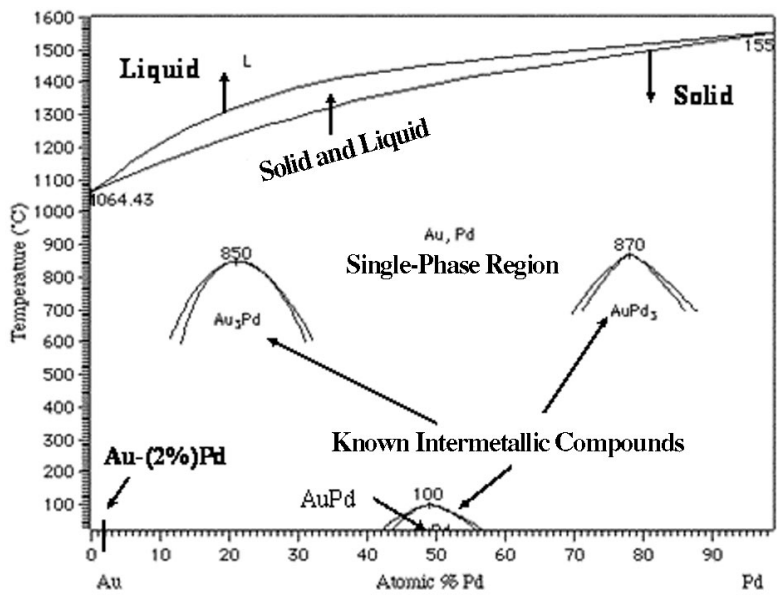

(b)

Figure 5. Equilibrium binary alloy phase diagrams used for selecting single-phase (a) gold-platinum (Au-Pt) and (b) goldpalladium $(\mathrm{Au}-\mathrm{Pd})$ alloys. 
The Au-Ni alloy composition that Schimkat studied was a stable, two-phase material. Due to variations in metal alloy deposition processes (i.e. temp, pressure, etc.), however, this precise $\mathrm{Au}-\mathrm{Ni}$ composition is difficult to reliably duplicate from fabrication run to fabrication run.

\section{EXPERIMENTAL SETUP}

A series of 20 micro-switches (10 Figure 1 and 10 Figure 2 designs) were tested on three different wafers (60 switches total) to experimentally characterize pull-in voltage, contact resistance, and switch lifetime. The experimental setup is illustrated in Figure 6.

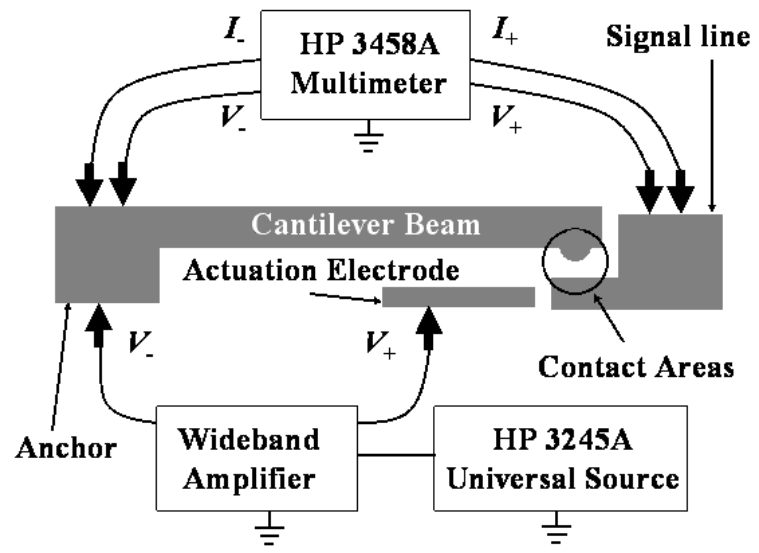

Figure 6. Schematic illustration of the experimental setup used to measure pull-in voltage, contact resistance, and switch lifetimes. The micro-switch depicted is a Figure 1 style device.

The micro-switches were tested by wafer probing using an Alessi Rel-4100A microprobe station with standard microprobes. The actuation voltage was applied using an HP 3245A universal source and a Krohn-Hite wideband amplifier. Closed switch resistance was measured using an HP 3458A multimeter in a fourpoint probe configuration. Contact resistance was found by subtracting the measured beam resistance from the closed switch resistance measurements.

During contact resistance testing, a voltage ranging from 0 to $110 \mathrm{~V}$ in $0.5 \mathrm{~V}$ increments was applied between the cantilever beam and the actuation electrode. The micro-switch closes when the actuation voltage exceeds the pull-in voltage $\left(V_{p i}\right)$. As the applied voltage is increased, beyond the pull-in voltage, contact force increases and contact resistance decreases. Contact resistance data were collected each time the actuation voltage was incremented.

During lifecycle testing, the micro-switches were actuated with a $50 \%$ duty cycle square wave input. The waveform's "on" voltage level was set to $V_{p i}$ plus approximately 1-5 $V$ for increased contact force. The input waveform's frequency was set below the beam's resonant frequency. The micro-switches were cycled continuously until they failed open (i.e. infinite resistance) or closed (i.e. stuck down). Contact resistance data were collected every 30 seconds by increasing the input waveform's duty cycle to $90 \%$ and lowering its frequency to $1 \mathrm{~Hz}$ for 2 seconds. The multimeter's open circuit voltage of $(\sim 8.2 \mathrm{~V})$ was present on the electric contacts for all the switching events (i.e. "hot-switching"). The success criteria for this testing was closed switch resistance of less than approximately $3 \Omega$ and infinite open switch resistance.

\section{RESULTS COMPARISON}

Contact resistance versus actuation voltage data, for selected micro-switches, are plotted on Figure 7. The Figure 1 style microswitch, with different contact metals, is compared on Figure 7(a) and the Figure 2 style micro-switch is compared on Figure 7(b).

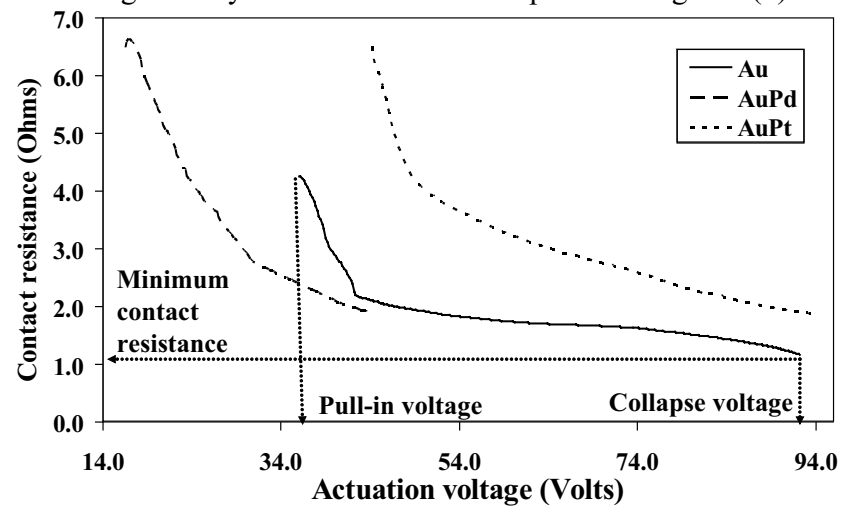

(a)

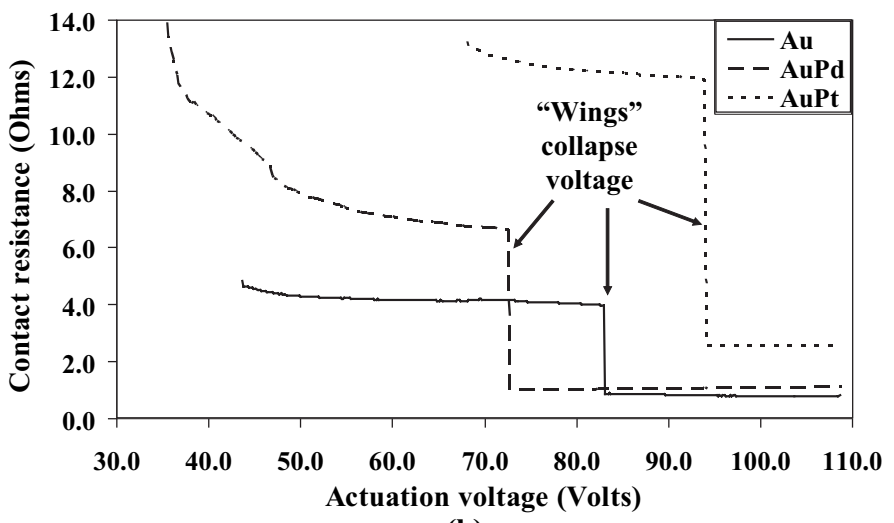

(b)

Figure 7. Contact resistance vs. actuation voltage data plots for selected micro-switches: (a) Figure 1 design (b) Figure 2 design.

Figure 7(a) (Figure 1 design) shows that pull-in and beam collapse voltages are located at the lower end of the voltage axis (higher contact resistance values) and the higher end of the voltage axis (lower contact resistance values), respectively. Minimum contact resistance is observed immediately prior to reaching the beam collapse voltage. Once the beam collapses onto the actuation electrode, the Figure 1 micro-switch shorts out and is no longer operable. The pull-in voltage, collapse voltage, and minimum contact resistance, for a Figure 1 micro-switch with sputtered $\mathrm{Au}$ electric contacts, are highlighted on Figure 7(a).

Figure 7(b) (Figure 2 design) shows pull-in voltages, located at the lower end of the voltage axis, and minimum contact resistance values, located at the higher end of the voltage axis. A sharp decrease in contact resistance, labeled as the "wings" collapse voltage on Figure 7(b), is observed. We believe that this anomaly was caused by the Figure 2 micro-switch upper contacts impacting the bottom contact "wings" prior to reaching the planar portion of the bottom contact. Bottom contact "wings" are illustrated on Figure 8(a). This anomaly did not cause the Figure 2 micro-switches to short because the electric contact bumps did not allow the beam to come into contact with the actuation electrode. Figure 1 micro-switches did not exhibit this anomaly because the bottom contacts were larger and the "wings" were $\sim 20 \mu \mathrm{m}$ away from the upper contact bumps. The larger Figure 1 bottom contacts are illustrated in Figure 8(b). 


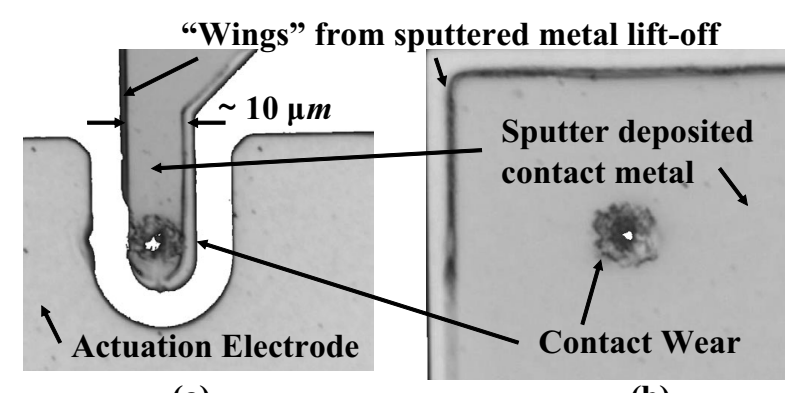

(a)

(b)

Figure 8. A captured video image illustrating wear on Au-(6\%)Pt lower electric contacts: (a) Figure 2 design and $\sim 8.8 * 10^{8}$ switch cycles (b) Figure 1 design and $\sim 2.7 * 10^{8}$ cycles.

The pull-in voltages and minimum contact resistance values, depicted on Figure 7, are summarized in Table 1. As expected, the measured contact resistance values for micro-switches with metal alloy electric contacts was higher than for devices with Au electric contacts.

Table 1. Summary of pull-in voltage $\left(V_{p i}\right)$ and minimum contact resistance $\left(R_{c}\right)$ measurements found on Figure 7.

\begin{tabular}{cccc}
\hline \hline \multicolumn{2}{c}{ Contact Metals } & $V_{p i}(V)$ & Min. $R_{c}(\Omega)$ \\
\hline \hline $\mathrm{Au}$ & (Figure 1 design) & 36.2 & 1.2 \\
& & & \\
\hline $\mathrm{Au}-(2 \%) \mathrm{Pd}$ & (Figure 1 design) & $16.5^{*}$ & 1.9 \\
& & & \\
\hline $\mathrm{Au}-(6 \%) \mathrm{Pt}$ & (Figure 1 design) & 44.3 & 1.9 \\
& & & \\
\hline $\mathrm{Au}$ & (Figure 2 design) & 43.5 & 3.9 \\
& & $(83.3)^{* *}$ & $(0.9)^{* *}$ \\
\hline $\mathrm{Au}-(2 \%) \mathrm{Pd}$ & (Figure 2 design) & $28.7^{*}$ & 6.7 \\
& & $(75.2)^{* *}$ & $(1.0)^{* *}$ \\
\hline $\mathrm{Au}-(6 \%) \mathrm{Pt}$ & (Figure 2 design) & 68.3 & 11.7 \\
& & $(94.1)^{* *}$ & $(2.6)^{* *}$ \\
\hline \hline
\end{tabular}

* Devices on this wafer exhibited lower pull-in voltage due to a thinner $(3.2-4.2 \mu \mathrm{m})$ than expected beam thickness.

** "Wings" collapse voltage and corresponding contact resistance.

Contact resistance versus switch cycle data, for selected micro-switches, are plotted on Figure 9.

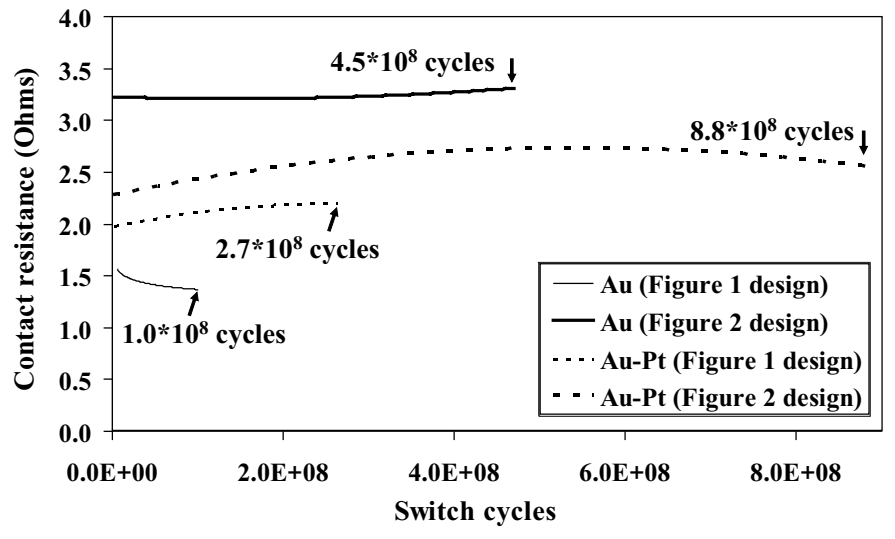

Figure 9. Contact resistance vs. switch cycles data plots.

The raw lifecycle data was curve fitted and the resulting trendlines were plotted on Figure 9. Micro-switches fabricated with $\mathrm{Au}-(2 \%) \mathrm{Pd}$ electric contacts were not effectively lifecycle tested because all of the devices exhibited lower than usually

restoring force due to a thinner than expected $(\sim 3.2-4.2 \mu \mathrm{m}$ versus $\sim 5 \mu \mathrm{m}$ ) electroplated Au beam thickness. The low restoring force is evidenced by the low measured pull-in voltages, for microswitches on the $\mathrm{Au}-(2 \%) \mathrm{Pd}$ wafer, that are illustrated in Figure 7 and summarized in Table 1.

Generally, micro-switches with Au electric contacts are limited to $\sim 10^{6}$ "hot-switched" cycles because evaporated Au (typical micro-switch bottom contact metal) is a soft metal and prone to wear [2]. Majumder, et al. reports greater than $10^{7}$ "hotswitched" cycles and $\sim 10^{11}$ "cold-switched" cycles for devices with "platinum group" electric contacts [2]. Duffy, et al. does not report lifetime results for their switches with Pt contacts [3].

The micro-switches with metal alloy electric contacts, in this study, were "hot-switched" and exhibited approximately 2-2.7 times longer lifetimes than devices with sputtered $\mathrm{Au}$ electric contact metals. This was most likely due to the increased material hardness of the sputtered metal alloys. Also, the switches with sputtered Au contacts, in this study, outperformed other microswitches with evaporated $\mathrm{Au}$ contacts [2]. Once again, this was most likely due to the increased material hardness of the sputtered $\mathrm{Au}$ contact metals. The measured Meyer hardness of evaporated $\mathrm{Au}$, sputtererd $\mathrm{Au}$, and sputtered $\mathrm{Au}-(6 \%) \mathrm{Pt}$ thin $(500 \AA)$ films were $\sim 1 G P a, \sim 2 G P a, \sim 2.2 G P a$, respectively.

\section{CONCLUSIONS}

The purpose of this work was to show the design, fabrication, and test results for micro-switches with metal alloy electric contacts, optimized for increased wear $\left(>10^{8}\right.$ "hotswitched" cycles), low contact resistance (1-2 $\Omega$ ), and actuation voltages less than approximately $65 \mathrm{~V}$. Overall, the results in this study show increased micro-switch wear performance at the expense of a small increase in contact resistance.

\section{ACKNOWLEDGEMENTS}

This work was sponsored by the Materials and Manufacturing Directorate, Air Force Research Laboratory, USAF, under project order number QGWSML02722002, POC: Dr. Robert L. Crane. The authors would like to acknowledge the Sensors Directorate, Air Force Research Laboratory, in particular, Dr. Rob Reid, Dr. Jack Ebel, Dr. Rick Strawser, Dr. Becky Cortez, and Dr. Kevin Leedy for switch design inputs and helping develop the custom micro-switch fabrication process.

\section{REFERENCES}

1. D. Peroulis et al., "Electromechanical Considerations in developing Low-Voltage RF MEMS Switches", IEEE Trans.ns on Microwave Theory and Techniques, 51:1 (2003), pp. 259-270.

2. S. Majumder et al., "MEMS Switches", IEEE Instrumentation and Measurement Magazine, Mar 2003, pp. 12-15.

3. S. Duffy et al., "MEMS Microswitches for Reconfigurable Microwave Circuitry", IEEE Wireless and Components Letters, 11:3 (2001), pp. 106-108.

4. J. Schimkat, "Contact measurements providing basic design data for microrelay actuator", Sensors and Actuators, A., 73 (1999), pp. 138-143.

5. R. Holm, Electric Contacts: Theory and Applications, (Berlin, Springer, 1967).

6. MicroChem Corp., http://www.microchem.com, 2003.

7. H. Baker, ed., ASM Handbook Volume 3 Alloy Phase Diagrams, (Ohio, ASM International, 1992). 